\title{
Effects of GBR 12909 and cocaine on cocaine-maintained behavior in rhesus monkeys
}

\author{
Paul Skjoldager ${ }^{a}$, Gail Winger ${ }^{a}$ and James H. Woods ${ }^{a, b}$ \\ ${ }^{a}$ Department of Pharmacology and ${ }^{b}$ Psychology, University of Michigan, Ann Arbor, MI 48109, (USA)
}

(Accepted February 9, 1993)

\begin{abstract}
The reinforcing effect of the high affinity dopamine reuptake inhibitor GBR 12909 (1-[2-[bis(4-fluorophenyl)methoxy]ethyl)4(3-phenylpropyl)piperazine) was compared with that of cocaine, and the effects of both GBR 12909 and cocaine pretreatments were evaluated on behaviour maintained by cocaine in rhesus monkeys. Increasing dose per injection of intravenously-delivered GBR 12909 or cocaine led to increased rates of lever-press responding. Maximum cocaine-maintained rates were higher and occurred at a smaller dose than maximum rates of GBR 12909-maintained responding. Presession intravenous administration of either GBR 12909 or cocaine $(0.32,1.0$ or $3.2 \mathrm{mg} / \mathrm{kg})$ resulted in dose-dependent decreases in rates of cocaine-maintained responding when high doses of cocaine, which engendered high response rates, were available early in the session. Under these conditions, the decrease in response rates was associated primarily with decreases in running rate rather than with a lengthening in post-reinforcement pause times. The decreases in running rate produced by both cocaine and GBR 12909 probably reflect an unconditioned rate-disruptive effect of these drugs on cocaine-reinforced responding rather than a reduction in the reinforcing efficacy of cocaine.
\end{abstract}

Key words: cocaine; GBR 12909; self-administration; post-reinforcement pause; running rate; fixed ratio; rhesus monkeys

\section{Introduction}

One of the most widely proposed pharmacotherapies for drug abuse is the use of agents that have some effects in common with the abused drug. Methadone, an opioid agonist with many heroin-like properties, is one of the most effective treatments of heroin abuse. The advantage of methadone, given orally, is that it is acceptable to heroin abusers, resulting in compliance with the therapy, and its long duration of action appears to prevent the debilitating cycles of psychological 'highs' and 'lows' that characterize heroin abuse (Dole et al. 1966). Application of this approach to the treatment of cocaine abuse might involve the use of drugs that have a mechanism similar to cocaine, but are longacting. An additional requirement, that is more

Correspondence to: Paul Skjoldager Ph.D., Memphis State University, Department of Psychology, Room 202, Memphis, TN 38152, USA. of a concern with psychomotor stimulants than with the relatively safe opioids, is that the treatment drug be effective in suppressing cocaine self-administration at non-toxic doses.

A similar mechanism to cocaine and a long duration of action would be expected from drugs that bind to and dissociate slowly from the dopamine-reuptake site at which cocaine is thought to act to produce many of its pharmacological effects, including its capacity to function as a reinforcer (Ritz et al., 1987). GBR 12909 is a potent dopamine uptake inhibitor (Berger et al., 1990) that is difficult to wash from this site of action (Rothman et al., 1989). It produces long-lasting $(6 \mathrm{~h})$, but small, increases in extracellular dopamine levels, and prevents binding of other dopamine reuptake inhibitors (Rothman et al., 1989). Furthermore, cocaine is significantly less able to increase levels of extracellular dopamine following systemic pretreatment with GBR 12909 to rats (Rothman et al., 1989). It is therefore possible that GBR 12909 
would act selectively to suppress cocaine selfadministration. The potential use of this drug or drugs like it as adjuncts in the treatment of cocaine abuse in humans has been suggested (Rothman et al., 1989; Rothman, 1990).

GBR 12909 has many behavioral effects in common with cocaine in both rats and monkeys, suggesting a similar behavioral action. In rats, GBR 12909, like cocaine, produced ipsilateral circling following 6-OHDA treatment (Heikkila and Manzino, 1984) and produced a cocaine-like discriminative stimulus effect (Witkin et al., 1991). GBR 12909 was self-administered by squirrel monkeys (Bergman et al., 1989; Howell and Byrd, 1991) and by rhesus monkeys (Kleven et al., 1988). It produced cocaine-like, doserelated increases in response rates in monkeys trained under an FI schedule of stimulus-shock termination (Spealman et al., 1989; Howell and Byrd, 1991). It substituted for cocaine in a cocaine-stimulus discrimination procedure in rhesus monkeys (Kleven et al., 1990), and squirrel monkeys trained to discriminate intravenous injections of GBR 12909 generalized to cocaine as well as to several other dopamine reuptake inhibitors (Melia and Spealman, 1991). The behavioral effects of GBR 12909 , like those of cocaine, were antagonized by D1 and D2 antagonists (Howell and Byrd, 1991).

The safety of GBR 12909 relative to cocaine has yet to be determined. The safety of a drug used to treat cocaine abuse through a cocainelike mechanism might be suggested if it generated a therapeutic index (ratio of toxic dose to effective dose) that was more favorable than that of cocaine itself. If GBR 12909 suppresses cocaine-maintained responding at doses that are well below those that produce behavioral toxicity, its usefulness in treating cocaine abuse becomes more likely.

In the present study, the reinforcing effects of GBR 12909 and cocaine were measured to determine the relative capacity of GBR 12909 to maintain responding, and to establish the relatively potencies of GBR 12909 and cocaine in rhesus monkeys using an IV route of administration. The effects of GBR 12909 and cocaine on cocaine self-administration were then com- pared. Thus, GBR 12909 and cocaine were evaluated in two preparations so that their relative potencies (and therapeutic indices), effectiveness, and duration of action could be determined.

\section{Methods}

\section{Subjects}

Two female (80N106, P671) and one male (R639) rhesus monkey (Macaca mulatta), cach with extensive histories of cocaine selfadministration, were used as subjects in the experiments. The monkeys were housed individually in experimental chambers with water and Purina High Protein Monkey Chow available at all times. Subjects were surgically implanted with intravenous catheters in either internal or external jugular veins, brachial or femoral veins. The silicone rubber catheters were passed subcutaneously from the site of the vein insertion to a mid-scapular exit site.

\section{Apparatus}

Each monkey wore a tubular stainless steel harness to which a hollow restraining arm was attached. The catheter passed from the monkey through the restraining arm to the outside of the cage where it attached to a roller infusion pump (Watson and Marlow Co., Model MHRK 55, Falmouth, UK) and necessary filters, valves, and bags of sterile vehicle and drug solutions. Infusion pumps were calibrated to deliver 0.2 $\mathrm{ml} / \mathrm{s}$.

The home cage, also serving as the experimental chamber, was made of plate and barred stainless steel, and measured $83.3 \times 76.2 \times$ $91.4 \mathrm{~cm}$. A $15.4-\mathrm{cm}^{2}$ stimulus-manipulandum panel was located on one wall of the cage, approximately $10 \mathrm{~cm}$ from the front and $19 \mathrm{~cm}$ from the floor of the cage. The top half of this panel consisted of three circular $2.5-\mathrm{cm}$ diameter openings, centered $2.5 \mathrm{~cm}$ apart, with clear plastic coverings. The center opening could be illuminated from behind by a green $5 \mathrm{~W}$ light, and the right opening could be illuminated with a red $5 \mathrm{~W}$ light. The left opening was never illuminated. Centered below the left and right 
openings were stainless steel response levers (BRS-LVE, Model 121-07, Beltsville, MD) capable of being operated by $10-15 \mathrm{~g}$ of force. Lever press responses were detected, and stimuli and injections were presented by interface equipment connected to IBM PCjr microcomputers.

\section{Procedure}

Subjects were trained to self-administer cocaine using a procedure much like that described by Winger et al. (1989). Two experimental sessions were conducted daily; one from 1000 to $1210 \mathrm{~h}$, the other from 1600 to $1810 \mathrm{~h}$. An experimental session consisted of four $25 \mathrm{~min}$ response periods that were separated by $10 \mathrm{~min}$ timeout periods. A response period was signaled by illumination of the red light located over the operative (right) response lever; completion of 30 lever press responses (fixed-ratio 30, FR 30) resulted in an injection that was immediately followed by a 45-s timeout. The red light was turned off during the timeouts separating response periods and following drug injections. Response periods ended when subjects obtained 20 injections or 25 min elapsed.

A different dose of cocaine was available during each of the four response periods. Doses were $0.001,0.003,0.01$, and $0.03 \mathrm{mg} / \mathrm{kg}$ per injection. Different doses were associated with infusion durations of $0.5,1.7,5$ and $16.7 \mathrm{~s}$. In order to allow access to a higher dose range of GBR 12909 during GBR 12909 self-administration tests, the monkeys were given access to two higher doses by using the same four infusion durations and a higher concentration of injected drug. Only four doses were assessed in any given session. The dose of drug available during a particular response period was not signalled. To decrease the likelihood that the monkeys were responding based on an expectancy of a particular dose sequence, doses were available in one of four orders (Latin square counterbalanced) on each session. Orders included a strictly ascending and a strictly descending order and two mixed orders. Data shown below on comparisons of rates of cocaine- and GBR 12909-maintained responding include all avail- able orders which were randomly selected. Because of the time-limited effects of cocaine and GBR 12909, the effects of presession administration of these drugs were assessed under conditions in which the doses of cocaine were available in either an ascending or descending order. These orders were analyzed separately so that clearer effects of the pretreatment drugs could be observed. Randomly selected dose orders were used between sessions in which pretreatments were given, but from these data, ascending and descending dose orders were selected as baseline controls for the data presented below. During baseline and pretreatment sessions, saline frequently (approximately one-third of the sessions) replaced cocaine as the solution delivered as a consequence of responding during an entire session. Rates of 0.5 responses/s or less were required on each of the four saline infusion durations before pretreatments were given or drug substitution changes were made.

Drug pretreatments were administered through the IV catheter either immediately (cocaine), or $30 \mathrm{~min}$ (GBR 12909) before an experimental session of cocaine availability. Pretreatments were not given prior to saline or GBR access. The effects of $0.32,1.0$ and $3.2 \mathrm{mg} / \mathrm{kg}$ cocaine or GBR 12909 pretreatments were assessed in single experimental sessions which were separated by at least three baseline (cocaine or saline) sessions. Approximately one-half of the cocaine and GBR 12909 pretreatment tests were conducted during the afternoon experimental sessions.

\section{Data analysis}

Rates of responding maintained by cocaine and by GBR 12909 were averaged for each monkey, at each dose, for the two to four sessions where monkeys had access to cocaine or GBR 12909. Three dependent measures were used to describe the effects of pretreatments on cocuine self-administration. Overall rate maintained by each dose of cocaine was calculated by dividing the total number of responses emitted during the 25-min response period by the amount of time in seconds available to respond (exclusive 
of time spent in postinjection timeouts and the time of the drug infusion). Running rate was the rate of responding in responses/s from the first response of the ratio to the completion of 30 lever presses. Running rate values were obtained for each ratio completed and were then averaged for each dose to obtain single values. If 30 lever presses were not completed, this running rate was discarded. Post-reinforcement pause time was obtained by determining the time in seconds elapsing from the onset of the red stimulus light, following delivery of a reinforcer, to the first lever press response. Latency to the first response after the initial onset of the red stimulus light in each component, prior to delivery of the first reinforcer, was calculated separately. Post-reinforcement pause data were averaged over the 25 -min response period for each dose to obtain single values. These data were averaged across the three monkeys. Data on saline substitution represent the average overall rate, running rate, and post-reinforcement pause time of saline-maintained responding across the four infusion durations when saline was substituted for cocaine. The cocaine and saline substitution sessions that most immediately preceded pretreatment or GBR 12909 substitution sessions were averaged and used as control values for both pretreatment effects and self-administration. These data are separated into ascending and descending orders as controls for drug effects on these respective dose orders.

\section{Drugs}

GBR 12909 was a generous gift of Novo Industri, Bagsvaerd, Denmark. GBR 12909 was dissolved in sterile water at concentrations below $5.0 \mathrm{mg} / \mathrm{ml}$. Concentrations up to $20 \mathrm{mg} / \mathrm{ml}$ were achieved by mixing GBR 12909 in sterile water with a small amount of $85 \%$ lactic acid and sonicating for $45 \mathrm{~min}$. Cocaine hydrochloride, purchased from Mallinckrodt, Inc, St. Louis, MO, was dissolved in sterile water.

\section{Results}

GBR 12909, on average, and within individual monkeys, did not maintain rates of responding as high as those maintained by cocaine (Fig. 1). Each of the three monkeys showed slight increases in rates of responding as the dose of GBR 12909 was increased from 0.01 to 0.1 $\mathrm{mg} / \mathrm{kg}$ per injection. The maximum average rate of responding, occurring at a dose of $0.1 \mathrm{mg} / \mathrm{kg}$ per injection GBR 12909, was 0.72 responses/s. In contrast, rates maintained by cocaine were maximum at an average of $1.57 \mathrm{responses} / \mathrm{s}$. These rates were maintained by a dose of 0.03 $\mathrm{mg} / \mathrm{kg}$ per injection of cocaine.

The effects of cocaine pretreatments on overall rates and patterns of responding are shown in Fig. 2. Under control conditions, with no pretreatment, increasing doses per injection of cocaine produced increases in rates of responding that corresponded primarily to decreases in post-reinforcement pause times. Presession administration of cocaine did not produce systematic, dose-related effects on rates of cocaine-maintained responding when the order of cocaine dose presentation was ascending (top, left panel). However, pretreatment with the largest dose of cocaine (3.2 $\mathrm{mg} / \mathrm{kg}$ ) produced marked decrements in running rates (middle, left panel).

In the descending dose-order series, the largest dose per injection of cocaine $(0.03 \mathrm{mg} / \mathrm{kg}$ per injection) was available immediately after intravenous cocaine pretreatment, and cocaine

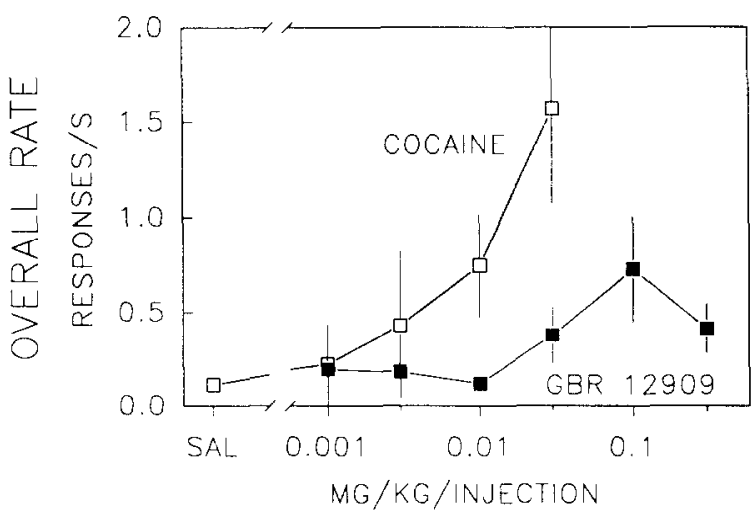

Fig. 1. Rates of responding maintained by either cocaine ( $\square$ ) or GBR 12909 ( $)$. The abscissa is dose of cocaine or GBR $12909 \mathrm{in} \mathrm{mg} / \mathrm{kg}$ per injection. The ordinate is rate of responding in response/s. Vertical bars indicate standard errors of the mean. 


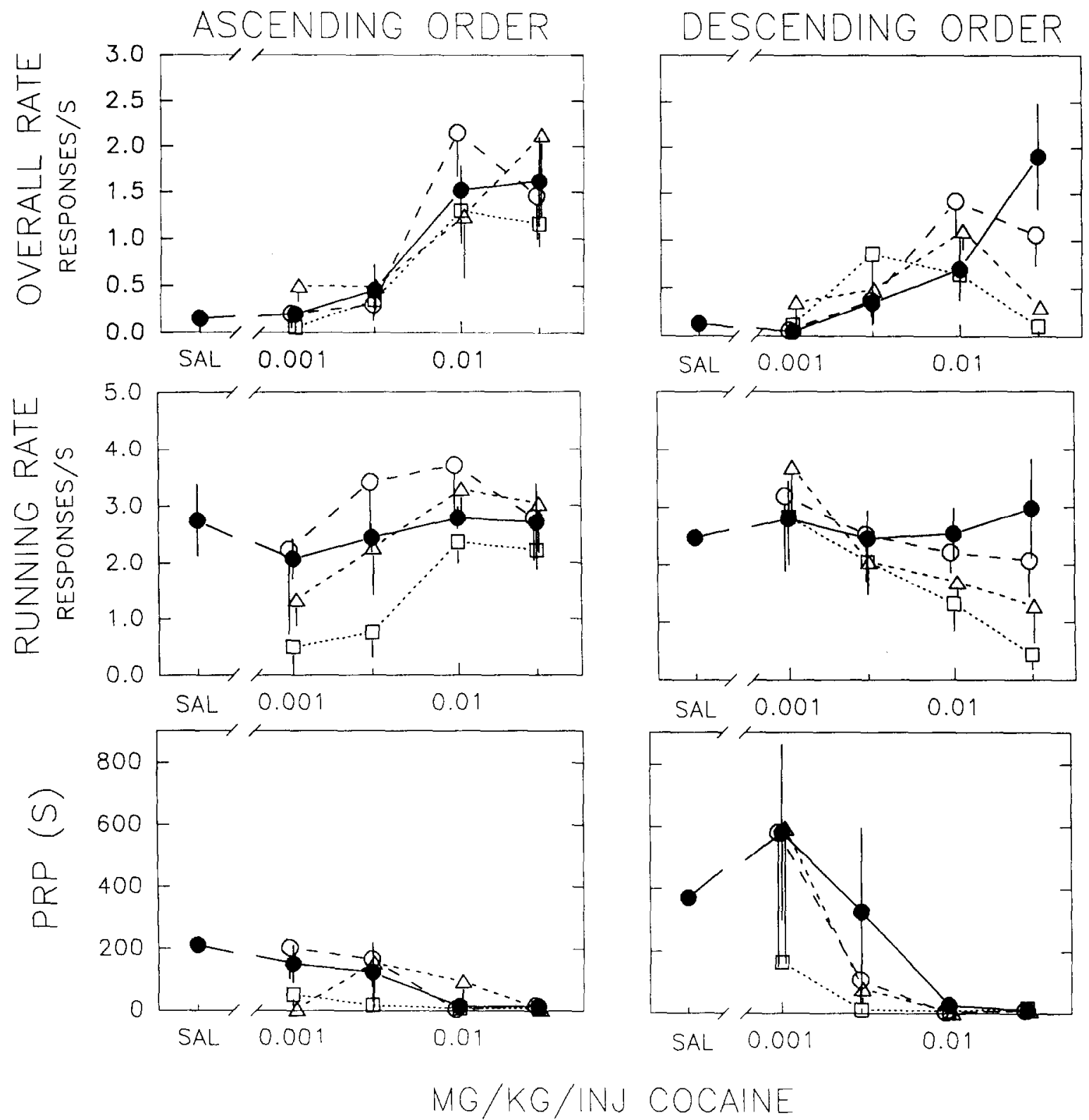

Fig. 2. The effects of administration of three doses of cocaine on behavior maintained by cocaine. Control data, averaged across sessions preceding test sessions, are indicated by ; the effects of $0.32 \mathrm{mg} / \mathrm{kg}$ cocaine are indicated by $\mathrm{O}$; the effects of $1.0 \mathrm{mg} / \mathrm{kg}$ cocaine are indicated hy $\Delta$; and the effects of $3.2 \mathrm{mg} / \mathrm{kg}$ cocaine are indicated by $\square$. The three panels on the left reflect the effects of cocaine pretreatment when the self-administered cocaine was available in an ascending dose order. The three panels on the right reflect the effects of cocaine pretreatment when the self-administered cocaine was available in a descending dose order. The abscissae are doses of self-administered cocaine in $\mathrm{mg} / \mathrm{kg}$ per injection. The ordinates are (top panels) overall rate of responding in responses per second; (center panels) running rate of responding in responses per second from the first response of a ratio to the completion of 30 responses; and (bottom panels) time (in seconds) elapsing from the onset of the stimulus indicating drug availability, after a prior drug delivery, to the first response. Vertical bars indicate standard errors of the mean. 


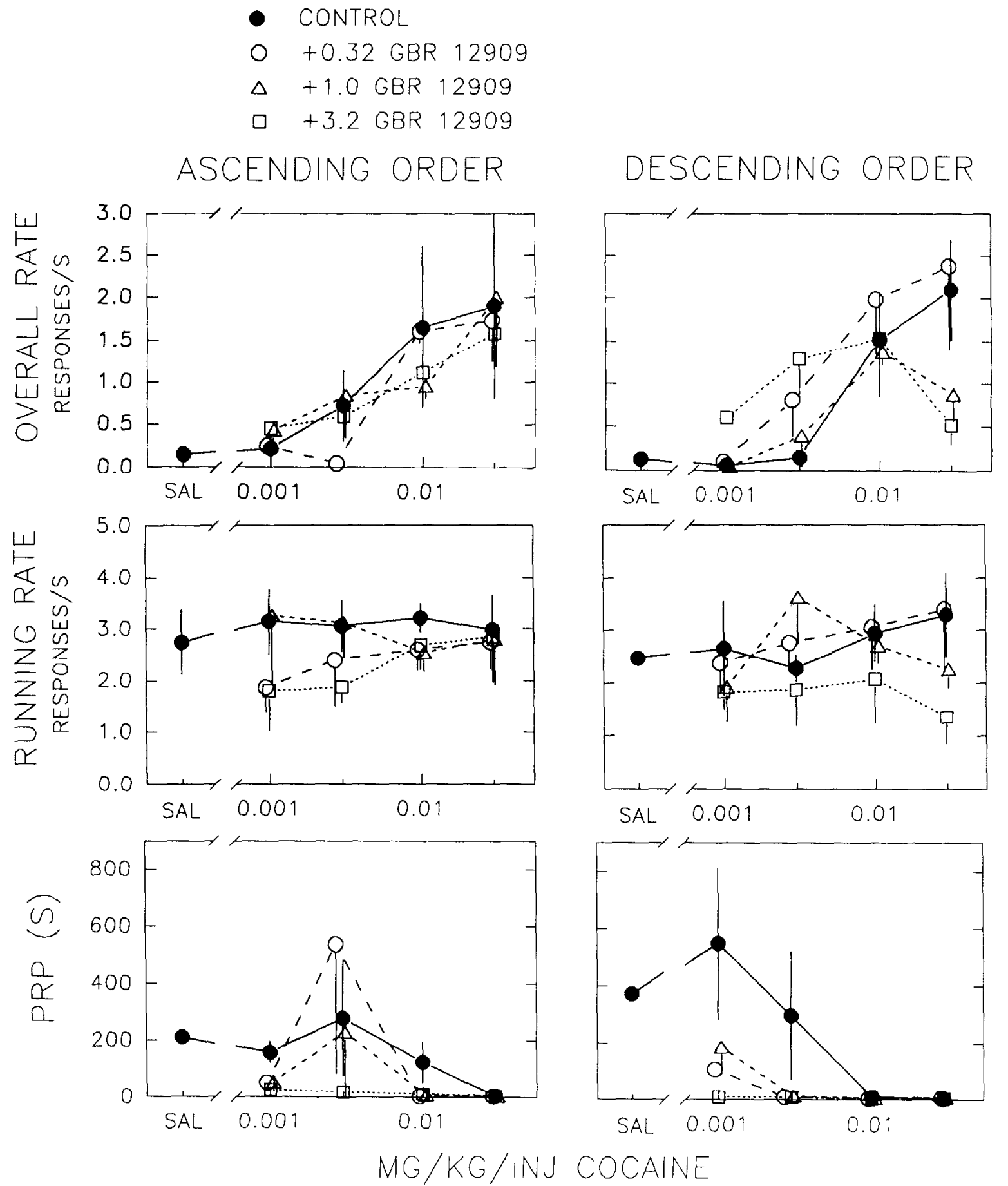

Fig. 3. The effects of administration of three doses of GBR 12909 on cocaine maintained behavior. Control data, averaged across sessions preceding test sessions, are indicated by 0 ; the effects of $0.32 \mathrm{mg} / \mathrm{kg} \mathrm{GBR} 12909$ are indicated by 0 ; the effects of $1.0 \mathrm{mg} / \mathrm{kg}$ GBR 12909 are indicated by $\Delta$; the effects of $3.2 \mathrm{mg} / \mathrm{kg}$ GBR 12909 are indicated by $\square$. Details of this figure are identical to those of Fig. 2. 
pretreatments produced dose-related decreases in overall response rates maintained by this largest dose per injection. The decreased rates of responses were accompanied by decreases in running rate (center, right panel) and little change in an already short post-reinforcement pause (bottom, right panel).

In general, presession administration of GBR 12909 had effects similar to cocaine on cocainemaintained responses (Fig. 3). During the ascending series, the largest dose of GBR 12909 pretreatment $(3.2 \mathrm{mg} / \mathrm{kg}$; a dose of $10 \mathrm{mg} / \mathrm{kg}$ produced convulsions in one monkey and marked stereotypies in another, and was not given to other animals) had virtually no effect on overall rates, but decreased running rates in the early part of the session and produced more pronounced decreases in post-reinforcement pause time throughout the session (middle and bottom, left panels). With the descending order of cocainedose presentation, both 1.0 and $3.2 \mathrm{mg} / \mathrm{kg}$ GBR 12909 produced suppression in rates maintained by the largest dose $(0.03 \mathrm{mg} / \mathrm{kg}$ per injection) of cocaine (top, right panel). This suppression was associated exclusively with an effect of these larger doses of GBR 12909 on running rate (center, right panel). GBR 12909 did not modify post-reinforcement pause time at the time it was suppressing rates of high-dose cocaine-maintained behavior (bottom, right panel). In contrast, the largest dose of GBR 12909 produced an increase in rates of responding maintained by the two smallest unit doses of cocaine (top, right panel) that was accounted for by a marked decrease in post-reinforcement pause time (bottom, right panel).

\section{Discussion}

GBR 12909 maintained maximum rates of responses that were well below those maintained by cocaine. In addition, the maximum rates of GBR 12909-maintained responding occurred at doses one half logarithm unit larger than doses of cocaine that maintained maximum rates of responses. A similar difference in potency between cocaine and GBR 12909 was found in studies of drug-maintained behavior (Bergman et al., 1989) and discriminative stimulus effects (Melia and Spealman, 1991) in squirrel monkeys. However, Howell and Byrd (1991) and Bergman et al. (1989) reported that rates of GBR 12909maintained responding were very similar to rates of cocaine-maintained responding. Our finding of low rates of GBR 12909-maintained responding might reflect differences in drug sensitivity between rhesus monkeys and squirrel monkeys, or might reflect the fact that Bergman et al. (1989) used a second order, fixed interval of fixed ratios, schedule of drug delivery, whereas we used a simple fixed ratio schedule. Kleven et al. (1988) reported that GBR 12909 maintained responding was greater than behavior maintained by saline in rhesus monkeys under a simple fixed ratio schedule, but these investigators did not indicate whether GBR 12909-maintained behavior comparable to that maintained by cocaine, and therefore do not provide assistance in clarifying this question.

Neither cocaine nor GBR 12909, even when administered in nearly convulsant doses, produced more than slight and/or transient suppressant effects on cocaine self-administration. The dose-related overall rate suppressant effects of both GBR 12909 and cocaine on cocainemaintained responding tended to occur only in the initial 25-min response period, and only when the largest dose of cocaine was available in this initial session segment, suggesting a short duration of action for both pretreatment drugs. More long-lasting effects of both cocaine and GBR 12909 can be observed in measures of running rate and post-reinforcement pause, but the greatest effects, particularly of cocaine, continued to occur during the initial component of the session. The largest dose of cocaine produced a greater suppression of running rates than did the largest dose of GBR 12909. Although administration of GBR 12909 immediately prior to a session rather than with a 30 -min pretreatment time might have caused the drug to have a greater effect on cocaine self-administration than is shown here, it might have obscured the fact that this drug, with a putative long duration 
of action and slow receptor dissociation kinetics (Rothman et al., 1989) is, in fact, quite shortacting in this preparation.

Drugs with cocaine-like actions have been suggested for treatment of cocaine abuse in humans (Gawin, 1988). In experimental studies in baboons, continuous infusions of amantadine, a drug that increases brain dopamine release, have been shown to reduce cocaine selfadministration behavior (Sannerud and Griffiths, 1988), but toxic sequelae of psychomotor stimulation and decreased food intake accompanied these suppressant effects. Interestingly, amantadine itself did not maintain selfadministration behavior in baboons (Sannerud and Griffiths, 1988). Bromocriptine, a dopamine receptor agonist that did maintain selfadministration behavior (Woolverton et al., 1984), reduced rates of cocaine-maintained responding in rhesus monkeys when given as a continuous infusion (Kleven and Woolverton, 1990). In some monkeys, cocaine-maintained responding was suppressed by bromocriptine more effectively than was food-maintained responding. However, even in these monkeys, bromocriptine had selective effects within a very narrow dose range and produced obvious stimulation in motor behavior. The authors interpreted the effects of bromocriptine as enhancing the effects of cocaine, but they could not distinguish between enhancement of the reinforcing effects of cocaine and enhancement of the rate-decreasing effects of cocaine (Kleven and Woolverton, 1990).

Evidence in the studies presented here indicates that GBR 12909 enhanced the ratedecreasing effects of cocaine rather than modifying the reinforcing effects of cocaine. If GRR 12909 were a competitive antagonist of the reinforcing effects of cocaine, it would have produced a shift to the right in cocaine's dose-response curve in much the same manner that opioid antagonists have been shown to shift the doseeffect curve of an opioid agonist in this preparation (Winger et al., 1992). However, there is no reason to predict a competitive interaction between GBR 12909 and cocaine, since these drugs are both agonists in this system. Evidence for the nature of the interaction between GBR 12909 and cocaine is clearer in the data on running rate and post-reinforcement pause than from the overall rate of responding. This indication derives from the finding that the rate of responding once the first response was made (running rate) was not very sensitive to changes in cocaine dose. It was nearly the same, whether the largest tested unit dose of cocaine or saline was available contingent on lever pressing, suggesting that running rate did not reflect the reinforcing effects of the delivered fluid. Yet, running rate was the variable most affected by both GBR 12909 and by cocaine pretreatment. Post-reinforcement pause, on the other hand, increased as dose of cocaine decreased, suggesting a greater sensitivity of post-reinforcement pause to reinforcing effects of the drug over this tested dose range. Post-reinforcement pause was not increased by doses of GBR 12909 or cocaine that produced marked decrements in overall rate, suggesting that these pretreatments did not modify the reinforcing effects of cocaine. As demonstrated by Skjoldager et al. (1991), further increases in the unit dose of cocaine used to maintain responding produced decreases in overall rates of responding and decreases in running rate (or increases in run time as described by Skjoldager et al. 1991) but only variable changes in post-reinforcement pause. If, as some suggest (Johanson and Fischman, 1989), the decreased rates resulting from self-administration of larger doses of cocaine are due to unconditioned suppressant effects of cocaine, then decreases in running rate may be indicative of such unconditioned suppressant effects, providing further support for notion that GBR 12909 and cocaine, given as pretreatments, are enhancing the unconditioned rate-suppressant effects of cocaine.

In summary, the data described in this paper indicate that although GBR 12909 was less effective and slightly less potent in maintaining self-administration behavior than was cocaine, it had similar potency and effectiveness relative to cocaine in attenuating cocaine self-administration. Doses of both cocaine and GBR 12909 that were only slightly below those that produced 
convulsions were necessary to suppress cocaine self-administration. Interestingly, given the previous reports of slow dissociation of GBR 12909 from the dopamine-uptake site, GBR 12909, as well as cocaine, appeared to have a short duration of action; neither drug had marked effects beyond the initial $25 \mathrm{~min}$ of the session. Thus, GBR 12909 appears to lack both the safety and the long duration of action that we deemed necessary for a drug to have potential in the treatment of cocaine abuse.

\section{Acknowledgements}

The technical assistance of Laurie Heller and Kirsten Roberts is gratefully acknowledged. This research was supported by PHS grants, numbers DA 04403 and DA 05951.

\section{References}

Berger, P., Elsworth, J.D., Arroyo, J. and Roth, R.H. (1990) Interaction of $\left[{ }^{3} \mathrm{H}\right] \mathrm{GBR} 12935$ and GBR 12909 with the dopamine uptake complex in nucleus accumbens. Eur. J. Pharmacol. 177, $91-94$.

Bergman, J., Madras, B.K., Johnson, S.E. and Spealman, R.D. (1989) Effects of cocaine and related drugs in nonhuman primates. III. Self-administration by squirrel monkeys. J. Pharmacol. Exp. Ther. 251, 150-155.

Dole, V.P., Nyswander, M. and Kreek, M.J. (1966) Narcotic blockade. Arch. Int. Med. 118, 304-309.

Gawin, F.H. (1988) Chronic neuropharmacology of cocaine: progress in pharmacotherapy. J. Clin. Psychiatry 49, $11-16$.

Heikkila, R.E. and Manzino, L. (1984) Behavioral properties of GBR 12909, GBR 13069 and GBR 13098: Specific inhibitors of dopamine uptake. Eur. J. Pharmacol. 103, $241-248$.

Howell, L.L. and Byrd, L.D. (1991) Characterization of the effects of cocaine and GBR 12909, a dopamine uptake inhibitor, on behavior in the squirrel monkey. J. Pharmacol. Exp. Ther. 258, 178-185.

Johanson, C.E. and Fischman, M.W. (1989) The pharmacology of cocaine related to its abuse. Pharmacol. Rev. 41, $3-52$.

Kleven, M.S., Anthony, E.W., Nielsen, E.B. and Woolverton, W.L. (1988) Reinforcing and discriminative stimulus effects of GBR 12909 in rhesus monkeys. Neurosci. Abst. $1,305$.

Kleven, M.S., Anthony, E.W. and Woolverton, W.L. (1990) Pharmacological characterization of the discriminative stimulus effects of cocaine in rhesus monkeys. J. Pharmacol. Exp. Ther. 254, 312-317.

Kleven, M.S. and Woolverton, W.L. (1990) Effects of bromocriptine and desipramine on behavior maintained by cocaine or food presentation in rhesus monkeys. Psychopharmacology 101, 208-213.

Melia, K.F. and Spealman, R.D. (1991) Pharmacological characterization of the discriminative-stimulus effects of GBR 12909. J. Pharmacol. Exp. Ther. 258, 626-632.

Ritz, M.C., Lamb, R.J., Goldberg, S.R. and Kuhar, M.J. (1987) Cocaine receptors on dopamine transporters are related to self-administration of cocaine. Science 237, $1219-1223$.

Rothman, R.B. (1990) High affinity dopamine reuptake inhibitors as potential cocaine antagonists: A strategy for drug development. Life Sci. 46, 17-21.

Rothman, R.R., Mele, A., Reid, A.A., Akunne, H., Greig, N., Thurkauf, A., Rice, K.C. and Pert, A. (1989) Tight binding dopamine reuptake inhibitors as cocaine antagonists. Fed. Eur. Biochem. Soc. Lett. 257, 341-344.

Sannerud, C.A. and Griffiths, R.R. (1988) Amantadine: evaluation of reinforcing properties and effect on cocaine selfadministration in baboons. Drug Alcohol Depend. 21, 195-202.

Skjoldager, P., Winger, G. and Woods, J.H. (1991) Analysis of fixed-ratio behavior maintained by drug reinforcers. J. Exp. Anal. Behav. 56, 331-343.

Spealman, R.D., Madras, G.K. and Bergman, J. (1989) Effects of cocaine and related drugs in nonhuman primates. II. Stimulant effects on schedule-controlled behavior. J. Pharmacol. Exp. Ther. 251, 142-149.

Winger, G., Palmer, R.K. and Woods, J.H. (1989) Drugreinforced responding: rapid determination of doseresponse functions. Drug Alcohol Depend. 24, 135-142.

Winger, G., Skjoldager, P. and Woods, J.H. (1992). Effects of buprenorphine and other opioid agonists on alfentaniland cocaine-reinforced responding in rhesus monkeys. J. Pharmacol. Exp. Ther. 261, 311-317.

Witkin, J.M., Nichols, D.E., Terry, P. and Katz, J.L. (1991) Behavioral effects of selective dopaminergic compounds in rats discriminating cocaine injections. J. Pharmacol. Exp. Ther. 257, $706-713$.

Woolverton, W.L., Goldberg, L.I. and Ginos, J.Z. (1984) Intravenous self-administration of dopamine receptor agonists by rhesus monkeys. J. Pharmacol. Exp. Ther. 230, $678-683$. 